Check for updates

Cite this: Chem. Commun., 2017, 53, 7076

Received 8th May 2017,

Accepted 8th June 2017

DOI: $10.1039 / \mathrm{c} 7 \mathrm{cc} 03544 f$

rsc.li/chemcomm

\section{Encapsulation of a $\left\{\mathrm{Cu}_{16}\right\}$ cluster containing four $\left[\mathrm{Cu}_{4} \mathrm{O}_{4}\right]$ cubanes within an isopolyoxometalate $\left\{\mathrm{W}_{44}\right\}$ cluster $\dagger$}

\author{
Caihong Zhan, Christoph Busche, De-Liang Long, (D) Pedro I. Molina, \\ Ross S. Winter and Leroy Cronin (iD *
}

\begin{abstract}
We report a $\left\{\mathrm{Cu}_{16}\right\}$ embedded within a $\left\{\mathrm{W}_{44}\right\}$ cluster containing four cubane-like $\left[\mathrm{Cu}_{4} \mathrm{O}_{4}\right]$ units within an isopolyoxotungstate (isoPOT) in a $\left\{\mathrm{Na}_{4} \mathrm{Cu}_{4}\left[\left(\mathrm{H}_{2} \mathrm{~W}_{11} \mathrm{O}_{38}\right)\left(\mathrm{CH}_{3} \mathrm{COO}\right)(\mathrm{OH})_{3}\right]\right\}_{4} \cdot 88 \mathrm{H}_{2} \mathrm{O}$ (1) and a polyanion Cu-linked $\left\{\mathrm{W}_{11}\right\}$ chain $\mathrm{Na}_{6} \mathrm{Cu}_{2}\left[\left(\mathrm{H}_{2} \mathrm{~W}_{11} \mathrm{O}_{38}\right)\left(\mathrm{CH}_{3} \mathrm{COO}\right)(\mathrm{OH})\right] \cdot 26 \mathrm{H}_{2} \mathrm{O}$ (2). Electronically, the redox properties show that both compounds 1 and 2 undergo irreversible reductions resulting in the demetalation of the compounds, whilst the magnetic behavior of 1 and 2 shows a weak antiferromagnetic and a stronger ferromagnetic coupling, respectively.
\end{abstract}

During the past decade many high nuclearity 3d-metal-based coordination complexes with interesting electronic and magnetic properties have been prepared. ${ }^{1}$ Polyoxometalates (POMs) are one such class of high-nuclearity inorganic clusters with structural and compositional diversity, and interesting potential applications in various fields. ${ }^{2}$ POM species can act as nucleophilic ligands for transition-metal (TM) or rare-earth cations and the coordination of magnetic centres can then lead to the formation of magnetic clusters whereby the POM can act as a ligand to organise many magnetic centres. ${ }^{3}$ Among the previous high nuclearity 3d-metal-based POMs reported to date, the vast majority of known structures show diamagnetic ligands derived from lacunary heteropolytungstates of the Keggin and WellsDawson types, encapsulating multinuclear paramagnetic 3d-metal-oxo cores. ${ }^{4}$

A remarkable class of 3d-metal-based POMs, characterized by a cubane-like $\left[\mathrm{M}_{4} \mathrm{O}_{4}\right]$ structure, is of interest for its electron transport and magnetic properties. ${ }^{5-7} \mathrm{~A}$ number of structural investigations of alkoxo-bridged $\mathrm{Cu}^{\mathrm{II}}$ tetramers with cubanelike $\left[\mathrm{Cu}_{4} \mathrm{O}_{4}\right]$ cores have been reported and their magnetic properties have been compared to the corresponding binuclear

WestCHEM, School of Chemistry, The University of Glasgow, Glasgow, G12 8QQ, UK. E-mail: Lee.Cronin@glasgow.ac.uk; Web: http://www.croninlab.com; Fax: +44 (0)141-330-4888; Tel: +44 (0)141-330-6650

$\dagger$ Electronic supplementary information (ESI) available: Full experimental procedures, crystallographic data, ESI-MS, TGA and CV analysis. CCDC 1547065 and 1547066. For ESI and crystallographic data in CIF or other electronic format see DOI: $10.1039 / \mathrm{c} 7 \mathrm{cc} 03544 \mathrm{f}$ complexes. $^{8}$ The super-exchange mechanism in these dimeric or cubane-like $\mathrm{Cu}^{\mathrm{II}}$ systems is interesting using inorganic diamagnetic POM ligands. As far as we know, there are no reports regarding isopolyanions encapsulating large paramagnetic 3d-metal-oxo cores. Herein, we have succeeded in preparing a tetrameric POM, containing four cubane-like $\left[\mathrm{Cu}_{4} \mathrm{O}_{4}\right]$ units in a hexadecacopper(II) core and four isoPOT $\left\{\mathrm{W}_{11}\right\}$ ligands via a simple, one-pot reaction.

Single-crystal X-ray diffraction analysis reveals that $\mathbf{1}$ comprises a central $\left\{\mathrm{Cu}_{16}\right\}$ core which is capped by four divacant isoPOTs $\left\{\mathrm{H}_{2} \mathrm{~W}_{11} \mathrm{O}_{38}\right\}$ units, resulting in an assembly with $D_{2 \mathrm{~d}}$ symmetry, see Fig. 1 . The $\left\{\mathrm{Cu}_{16}\right\}$ core comprises four cubanelike $\left[\mathrm{Cu}_{4} \mathrm{O}_{4}\right]$ units linked together to form a ring by acetate anions and $\mu_{2}$-hydroxo bridges (see Fig. 1). Compound 1 can also be viewed as four equivalent $\left\{\mathrm{Cu}_{4} \mathrm{~W}_{11}\right\}$ building blocks aggregated together in an idealized $D_{2 \mathrm{~d}}$ symmetry. In the building block, one divacant isoPOT $\left\{\mathrm{W}_{11}\right\}$ links to two dimers $\left\{\mathrm{Cu}_{2}\right\}$ via two $\mu_{2}$-oxo and one $\mu_{3}$-oxo bridges (see Fig. S1, ESI $\dagger$ ). In low $\mathrm{pH}$, four such building blocks condense to a tetrameric POM, containing four cubane-like $\left[\mathrm{Cu}_{4} \mathrm{O}_{4}\right]$ units in a hexadecacopper(II) core and four isoPOT $\left\{\mathrm{W}_{11}\right\}$ ligands, in which the $D_{2 \mathrm{~d}}$ symmetry is delivered from the cubic unit to outer $\left\{W_{44}\right\}$ shell. The detailed cubic unit is shown in Fig. S2 (ESI $\dagger)$. The protonated oxygen atoms were identified by bond valence sum (BVS) calculations

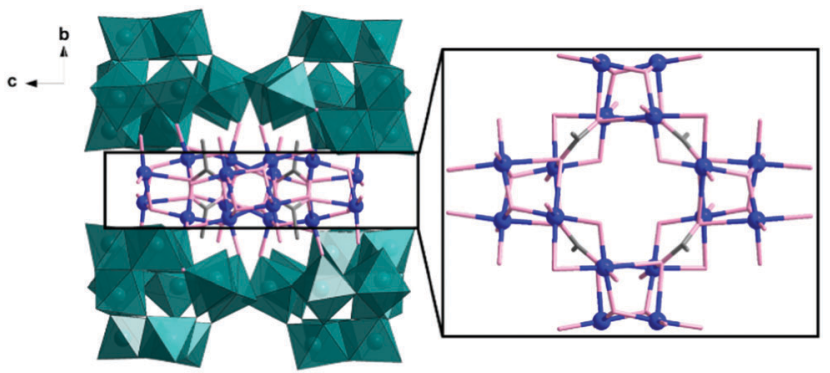

Fig. 1 Representation of the polyanion cluster of 1 (left) and the $\left\{\mathrm{Cu}_{16}\right\}$ core in the cluster (right). The $\left\{W_{11}\right\}$ building units are shown as teal polyhedra, $\mathrm{Cu}$ as blue sphere, $\mathrm{O}$ and $\mathrm{C}$ as rose and grey sticks. 
which indicated there are two protons located inside the $\left\{\mathrm{W}_{11}\right\}$ cluster. The formula was deduced using a range of methods including single crystal X-ray diffraction, microanalysis, inductively coupled plasma optical emission spectroscopy (ICP-OES) and thermogravimetric analysis (TGA) (see Fig. S3, S4, and ESI $\dagger$ for more detail).

To make POTs with a higher number of paramagnetic ions, precursors with multilacunary sites or higher negative charges are essential. The synthetic method we present here is a new simple and efficient way to produce such high-nuclearity 3d-metal-based POTs like 1. Our approach uses a simple onepot reaction of high concentrations of $\mathrm{Na}_{2} \mathrm{WO}_{4} \cdot 2 \mathrm{H}_{2} \mathrm{O}$ and $\mathrm{Cu}\left(\mathrm{CH}_{3} \mathrm{COO}\right)_{2}$ in an aqueous medium at raised temperatures $\left(80^{\circ} \mathrm{C}\right.$, to increase the solubility), by adding $\mathrm{HCl}$ acid drop-wise to condense the metal-oxide to self-assemble the final substituted POM. Considering that lacunary heteropolytungstates precursors normally form sandwich and banana shaped structures, ${ }^{9}$ which are usually difficult to encapsulate high-nuclearity $3 \mathrm{~d}$-metal ions in POTs, we did our experiment de novo and without any heteroatoms as so to avoid the formation of heteropolyacids. The other consideration is that isoPOTs have been shown to have extraordinary structural diversities for the special vacant sites, although the isoPOTs precursors are fragile under aqueous conditions, but the $3 \mathrm{~d}$-metal cations can act to anchor the vacant sites to produce novel stable 3d-metal substituted POTs. ${ }^{10}$

In this experiment, precise control of the reaction parameters including concentration, $\mathrm{pH}$, cation/anion type and the reagent ratio is crucial to produce pure $\mathbf{1}$ in high yield (see ESI $\dagger$ for more detail). In a parallel experiment when the $\mathrm{pH}$ was adjusted to 4 , the solution became clear blue, from which $\mathrm{Na}_{6} \mathrm{Cu}_{2}\left[\left(\mathrm{H}_{2} \mathrm{~W}_{11} \mathrm{O}_{38}\right)\left(\mathrm{CH}_{3} \mathrm{COO}\right)(\mathrm{OH})\right] \cdot 26 \mathrm{H}_{2} \mathrm{O}(2)$, a $1 \mathrm{D}$ polyanion chain structure, was obtained within one week. In the structure of 2 , the divacant isoPOT $\left\{\mathrm{W}_{11}\right\}$ is connected to a dimer of copper ions joined via two $\mu_{2}$-oxo, one $\mu_{3}$-oxo as observed in $\mathbf{1}$ (see Fig. 2). The oxo in the apical coordinate site of one copper is linked to an adjacent $\left\{\mathrm{W}_{11}\right\}$ unit $(\mathrm{Cu}-\mathrm{O}, 2.511(1) \AA)$ along the crystallographic $b$ axis. It is worth noting that in the structure, the POM units are arranged in an alternating fashion which acts to reduce the steric hindrance.

High resolution negative mode electrospray ionisation mass spectrometry (ESI-MS) was performed on crystalline samples to explore the stability of compounds $\mathbf{1}$ and $\mathbf{2}$ in solution (see $\mathrm{ESI} \dagger$ for more detail). Fig. S5 (ESI $\dagger$ ) shows the mass spectrum of $\mathbf{1}$, where the overlapping peaks in the region of $1400-1480 \mathrm{~m} / \mathrm{z}$

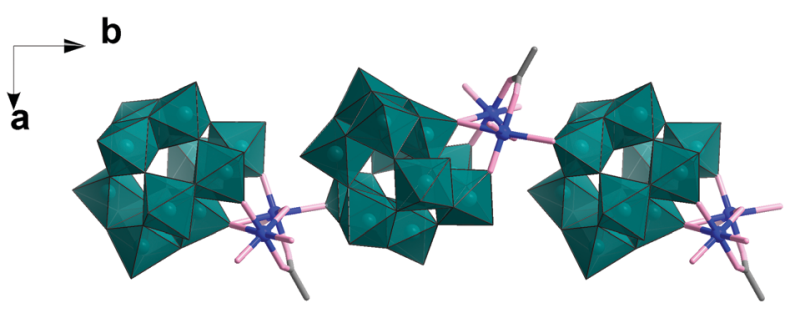

Fig. 2 Representation of the polyanion chain structure of 2 . The $\left\{W_{11}\right\}$ building units are shown as teal polyhedra, $\mathrm{Cu}$ as blue ball, $\mathrm{O}$ and $\mathrm{C}$ as rose and grey sticks. correspond to $\left\{\mathrm{Cu}_{2}\left(\mathrm{~W}_{11} \mathrm{O}_{38}\right)\right\}$ fragments with different numbers of associated $\mathrm{H}^{+}$and $\mathrm{Na}^{+}$ions and can be assigned as: $\left[\mathrm{Na}_{a-x} \mathrm{H}_{b+x} \mathrm{Cu}_{2}\left(\mathrm{~W}_{11} \mathrm{O}_{38}\right)\right]^{n-}$. The overlapping peaks in the region of $1480-1570 \mathrm{~m} / z$ correspond to cubic $\left\{\mathrm{Cu}_{4}\left(\mathrm{~W}_{11} \mathrm{O}_{38}\right)\right\}$ fragments with cations and different number of solvent molecules. This regular peak pattern strongly suggests the stability of the building blocks in solution. For compound 2, a series of sequentially charged peaks could be identified in the region of $680-1020 \mathrm{~m} / \mathrm{z}$ (Fig. S6, ESI $\dagger$ ), where the major peaks in the spectra were found to correspond to the hypothesised $\left\{\mathrm{Cu}_{2}\left(\mathrm{H}_{2} \mathrm{~W}_{11} \mathrm{O}_{38}\right)\right\}$ intermediate units with a mass of $c a .2 .8 \mathrm{kDa}$ (and a variable number of cations and solvent molecules of mass around a few hundred Da) (see $\mathrm{ESI} \dagger$ for more detail). This is significant as it provides evidence for the viability of our hypothesised assembly pathway in the formation of 2 from $\mathrm{Cu}$-substituted $\left\{\mathrm{W}_{11}\right\}$ units.

The electrochemical behavior of $\mathbf{1}$ and $\mathbf{2}$ was investigated by means of cyclic voltammetry (Fig. 3). The voltammogram of $\mathbf{1}$ in a buffered aqueous solution $(\mathrm{pH}=4.4)$ was recorded starting from a potential value of $+0.60 \mathrm{~V}$ and then scanning towards the cathodic region of the voltammogram (Fig. 3a). The first two reduction waves, peaking at $-0.04 \mathrm{~V}$ and $-0.08 \mathrm{~V}$, can be assigned to the two-step reduction of the $\mathrm{Cu}^{\mathrm{II}}$ centres. Thus, the first of these waves is caused by a $\mathrm{Cu}^{\mathrm{II}} / \mathrm{Cu}^{\mathrm{I}}$ reduction while the second wave is produced by the reduction of the $\mathrm{Cu}^{\mathrm{I}}$ centers, a process which is followed by the deposition of $\mathrm{Cu}^{0}$ on the surface of the electrode. On scan reversal, a rather intense, sharp wave peaking at $+0.05 \mathrm{~V}$ can be ascribed to the reoxidation of the deposited $\mathrm{Cu}^{0}$ to $\mathrm{Cu}^{\mathrm{II}}$ and its subsequent stripping from the electrode surface. Cycling the potential in a restricted region, i.e. where only the first reduction wave is observed, suggests that the $\mathrm{Cu}^{\mathrm{II}} / \mathrm{Cu}^{\mathrm{I}}$ reduction is not reversible (Fig. 3a, inset). A similar electrochemical behaviour of related $\mathrm{Cu}-\mathrm{POMs}$ has been previously reported. ${ }^{11}$ The deposition of $\mathrm{Cu}^{0}$ on the electrode surface during the cathodic scan must result in the decomposition of the cluster. This irreversible demetalation of the cluster explains the gradual decrease in current observed in the voltammograms obtained after a series of potential scans (Fig. S7, ESI $\dagger$ ). In addition to the $\mathrm{Cu}$-centred processes, two typical quasi-reversible wave couples $\left(E_{1 / 2}=-0.57 \mathrm{~V},-0.66 \mathrm{~V}\right)$ associated to redox processes for $\mathrm{W}^{\mathrm{VI}}$ based-species can also be observed in the cathodic
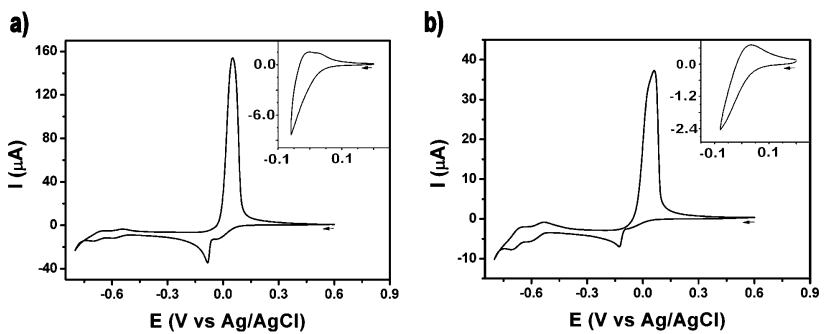

Fig. 3 Cyclic voltammogram of a solution of $\mathbf{1}$ (a) and $\mathbf{2}$ (b) $\left(2 \times 10^{-4} \mathrm{~mol} \mathrm{~L}^{-1}\right)$ in $\mathrm{NaCH}_{3} \mathrm{COO} / \mathrm{H}^{+}$buffer solution $(0.5 \mathrm{M}, \mathrm{pH}=4.4)$. Inset: Cyclic voltammogram of the same solution in a potential range restricted to the first reduction wave observed in the main voltammogram. In both cases, the scan rate was $5 \mathrm{mV} \mathrm{s}^{-1}$, while the working and counter electrodes were glassy carbon and Pt mesh respectively. 

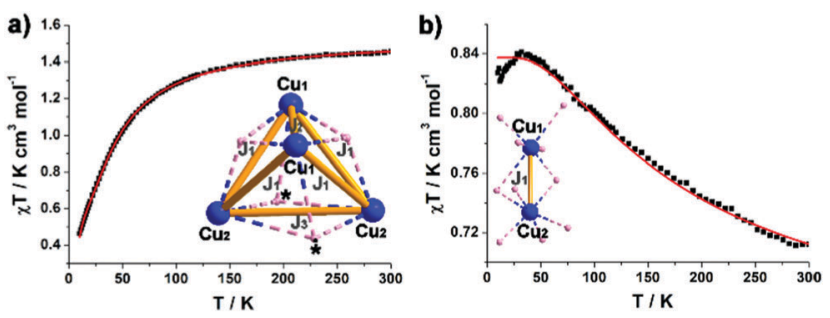

Fig. 4 Temperature dependence of $\chi_{M} T$ for 1 (a) and $\mathbf{2}$ (b) from 2-300 K at $500 \mathrm{Oe}$. Solid lines represent best fits to a Heisenberg-only model. Inset: Exchange connectivity within the cubic $\left\{\mathrm{Cu}_{4}{ }_{4}\right\}$ unit in 1 and dimmer $\left\{\mathrm{Cu}_{2}{ }_{2}\right\}$ unit in $\mathbf{2} \mathrm{CCu}^{\prime \prime}$ blue spheres, all other corners/intersections represent $\mu$-oxo groups, * represents the oxygen from acetate) illustrating the six principal superexchange pathways in 1 and one principal superexchange pathways in 2: $\mathrm{J}\left(\mathrm{Cu}^{\prime \prime}-\mathrm{Cu}^{\prime \prime}\right.$, light orange lines).

region of the voltammogram. The electrochemical behaviour of $\mathbf{2}$ is fairly similar to $\mathbf{1}$. A series of voltammograms recorded from 2 solutions under equivalent experimental conditions are shown in Fig. 3b and Fig. S8 (ESI $\dagger$ ). The reduction waves associated with the $\mathrm{Cu}^{\mathrm{II}} / \mathrm{Cu}^{\mathrm{I}}$ and the $\mathrm{Cu}^{\mathrm{I}} / \mathrm{Cu}^{0}$ processes in 2 $(-0.08 \mathrm{~V}$ and $-0.13 \mathrm{~V})$ are cathodically shifted with respect to the 1's values, a shift which is also slightly mirrored in the waves ascribed to the $\mathrm{W}^{\mathrm{VI}}$ centres $\left(E_{1 / 2}=-0.58 \mathrm{~V},-0.68 \mathrm{~V}\right)$.

The magnetic behaviour of microcrystalline samples of compound 1 and 2 has been studied in the range of 2 to $300 \mathrm{~K}$, and the results are shown in Fig. 4 in the form $\chi_{\mathrm{M}} T$ versus $\mathrm{T}$ plots $\left(\chi_{\mathrm{M}}=\right.$ molar magnetic susceptibility). The $\left\{\mathrm{Cu}^{\mathrm{II}}{ }_{16}\right\}$ unit in 1 has 16 unpaired electrons, considering $\left\{\mathrm{Cu}^{\mathrm{II}}{ }_{16}\right\}$ unit consists of four symmetrical cubic $\left\{\mathrm{Cu}_{4}^{\mathrm{II}}\right\}$ units with similar connectivity, the overall magnetic behaviour of $\mathbf{1}$ can be reduced to a cubic $\left\{\mathrm{Cu}_{4}{ }_{4}\right\}$ unit. The room-temperature $\chi_{\mathrm{M}} T$ value of $1.22 \mathrm{~cm}^{3} \mathrm{~mol}^{-1}$ $\mathrm{K}$ for $\mathbf{1}$ is lower than the spin-only value for a cubic $\left\{\mathrm{Cu}_{4}^{\mathrm{II}}\right\}$ unit $\left(1.4 \mathrm{~cm}^{3} \mathrm{~mol}^{-1} \mathrm{~K}\right.$ with $\left.g=2\right)$. The value of $\chi_{\mathrm{M}} T$ slowly decreases upon cooling and followed by a sharp decrease from $70 \mathrm{~K}$ (Fig. 4a), indicating an antiferromagnetic coupling at low temperature. In the simulation, a simplified spin Hamiltonian, based solely on an isotropic Heisenberg-type exchange $\hat{H}_{\mathrm{ex}}=-2 J_{\mathrm{ex}} \cdot \hat{S}_{1} \cdot \hat{S}_{2}$, was used to model the susceptibility data. As the $\left\{\mathrm{Cu}^{\mathrm{II}}{ }_{4}\right\}$ unit in $\mathbf{1}$ is a twisted cube with three different contacts, Cu1-Cu2, Cu1-Cu1 and Cu2-Cu2. Three types of nearest neighbour couplings can be identified (inset Fig. 4a). A least squares fit yields $J_{1}=-2.05 \mathrm{~cm}^{-1}, J_{2}=-29.9 \mathrm{~cm}^{-1}$ and $J_{3}=-4.6 \mathrm{~cm}^{-1}$ (common $g_{\text {iso }}=2.0$ ). For compound 2 , the value of $\chi_{\mathrm{M}} T$ at $300 \mathrm{~K}\left(0.56 \mathrm{emu} \mathrm{K} \mathrm{mol}{ }^{-1}\right)$ is lower than the spinonly value $\left(0.7 \mathrm{emu} \mathrm{K} \mathrm{mol}^{-1}, g=2.0\right)$ for two $\mathrm{Cu}^{\mathrm{II}}$ ions. Upon cooling, the value of $\chi_{\mathrm{M}} T$ gradually increases to a maximum of $0.82 \mathrm{emu} \mathrm{K} \mathrm{mol}^{-1}$, indicative of ferromagnetic interaction (Fig. 4b). The exchange interactions are grouped in $\mathrm{Cu} 1-\mathrm{Cu} 2$ contacts (inset Fig. $4 \mathrm{~b}$ ), each mediated by two $\mu$-O sites with Cu1-O-Cu2 angles approx. $90^{\circ}$. A least squares fit yields $J_{1}=$ $66.7 \mathrm{~cm}^{-1}$, (common $g_{\text {iso }}=1.83$ ). As we know, $\mathrm{Cu}_{2}(\mathrm{OAc})_{4}\left(\mathrm{H}_{2} \mathrm{O}\right)_{2}$ (the starting reagent in this work), which is essentially diamagnetic due to cancellation of the two opposing spins, was a critical step in the development of modern theories for antiferromagnetic coupling. ${ }^{12}$ The binuclear distance of $3.08 \AA$ in 2 is much longer than the $\mathrm{Cu}-\mathrm{Cu}$ separation of $2.62 \AA$ in
$\mathrm{Cu}_{2}(\mathrm{OAc})_{4}\left(\mathrm{H}_{2} \mathrm{O}\right)_{2}{ }^{13}$ The replacement of acetate with isoPOT $\left\{\mathrm{W}_{11}\right\}$ ligand largely changes the symmetry of the binuclear structure, which induces the obviously different magnetic behaviour in 2 compared with the dicopper acetate.

In summary, $\left\{\mathrm{Na}_{4} \mathrm{Cu}_{4}\left[\left(\mathrm{H}_{2} \mathrm{~W}_{11} \mathrm{O}_{38}\right)\left(\mathrm{CH}_{3} \mathrm{COO}\right)(\mathrm{OH})_{3}\right]_{4} \cdot 88 \mathrm{H}_{2} \mathrm{O}\right.$ (1), the unprecedented high-nuclearity $3 \mathrm{~d}$-metal based tetrameric isopolyoxotungstate was obtained via a simple, one-pot reaction. 1 is not only the first hexadeca-copper(II) core encapsulated by isopolyanion tungstate $\left\{\mathrm{W}_{11}\right\}$ units, but also an example of four cubane-like $\left[\mathrm{Cu}_{4} \mathrm{O}_{4}\right]$ units being contained within the core of a cluster. Furthermore, the control experiment, demonstrating the crucial role of $\mathrm{pH}$ in the self-assembly of $\mathbf{1}$, produced a 1D chain structure $\mathrm{Na}_{6} \mathrm{Cu}_{2}\left[\left(\mathrm{H}_{2} \mathrm{~W}_{11} \mathrm{O}_{38}\right)\left(\mathrm{CH}_{3} \mathrm{COO}\right)(\mathrm{OH})\right] \cdot 26 \mathrm{H}_{2} \mathrm{O}(2)$. The electrochemical behavior of 1 and 2 shows the gradual reduction of $\mathrm{Cu}^{\mathrm{II}} / \mathrm{Cu}^{\mathrm{I}}$ and then $\mathrm{Cu}^{\mathrm{I}} / \mathrm{Cu}^{0}$, followed, at more negative potential, by the reversible redox of the $\mathrm{W}$ centers. The magnetic behavior of $\mathbf{1}$ and $\mathbf{2}$ shows a weak antiferromagnetic and a stronger ferromagnetic coupling respectively, which was induced by their different configurations of copper ions with the POM and acetate ligands.

The authors would like to thank the EPSRC (grants $\mathrm{EP} / \mathrm{L} 023652 / 1, \mathrm{EP} / \mathrm{K} 023004 / 1, \mathrm{EP} / \mathrm{H} 024107 / 1, \mathrm{EP} / \mathrm{I033459/1}$ and $\mathrm{EP} / \mathrm{J} 015156 / 1$ ), the University of Glasgow, and the ERC (project 670467 SMART-POM) for supporting this work. We thank Dr Diana Castro for assistance with the MS measurements and Li Dong checking the reproducibility of the synthetic protocols presented here and we would like to thank Graham Newton and Hiroki Oshio with help recording the magnetic data.

\section{Notes and references}

1 (a) R. Sessoli, H. L. Tsai, A. R. Schake, S. Y. Wang, J. B. Vincent, K. Folting, D. Gatteschi, G. Christou and D. N. Hendrickson, J. Am. Chem. Soc., 1993, 115, 1804; (b) R. Sessoli, D. Gatteschi, A. Caneschi and M. A. Novak, Nature, 1993, 365, 141.

2 (a) A. Dolbecq, E. Dumas, C. R. Mayer and P. Mialane, Chem. Rev., 2010, 110, 6009; (b) D.-L. Long, R. Tsunashima and L. Cronin, Angew. Chem., Int. Ed., 2010, 49, 1736.

3 (a) C. Ritchie, A. Ferguson, H. Nojiri, H. N. Miras, Y.-F. Song, D.-L. Long, E. Burkholder, M. Murrie, P. Kögerler, E. K. Brechin and L. Cronin, Angew. Chem., Int. Ed., 2008, 47, 5609; (b) M. A. AlDamen, J. M. Clemente-Juan, E. Coronado, C. Marti-Gastaldo and A. Gaita-Arino, J. Am. Chem. Soc., 2008, 130, 8874; (c) J. Compain, P. Mialane, A. Dolbecq, I. M. Mbomekallé, J. Marrot, F. Sécheresse, E. Rivière, G. Rogez and W. Wernsdorfer, Angew. Chem., Int. Ed., 2009, 48, 3077.

4 (a) A. Giusti, G. Charron, S. Mazerat, J.-D. Compain, P. Mialane, A. Dolbecq, E. Rivière, W. Wernsdorfer, R. N. Biboum, B. Keita, L. Nadjo, A. Filoramo, J.-P. Bourgoin and T. Mallah, Angew. Chem., Int. Ed., 2009, 48, 4949; (b) M. A. AlDamen, S. Cardona-Serra, J. M. Clemente-Juan, E. Coronado, A. Gaita-Ariño, C. Marti-Gastaldo, F. Luis and O. Montero, Inorg. Chem., 2009, 131, 12558.

5 M. Ibrahim, Y. Lan, B. S. Bassil, Y. Xiang, A. Suchopar, A. K. Powell and U. Kortz, Angew. Chem., Int. Ed., 2011, 50, 4708.

6 C. Ritchie, A. Ferguson, H. Nojiri, H. N. Miras, Y.-F. Song, D.-L. Long, E. Burkholder, M. Murrie, P. Kögerler, E. K. Brechin and L. Cronin, Angew. Chem., Int. Ed., 2008, 47, 5609.

7 X. Fang, P. Kögerler, M. Speldrich, H. Schilderb and M. Luban, Chem. Commun., 2012, 48, 1218.

8 (a) F. Nepveu, Inorg. Chim. Acta, 1987, 134, 43; (b) S. S. Mal, B. S. Bassil, M. Ibrahim, S. Nellutla, J. van Tol, N. S. Dalal, J. A. Fernández, X. López, J. M. Poblet, R. N. Biboum, B. Kelta and U. Kortz, Inorg. Chem., 2009, 48, 11636.

9 M. M. Sabi, R. S. Winter, C. Lydon, J. M. Cameron, D.-L. Long and L. Cronin, Chem. Commun., 2015, 52, 919. 
10 C. Zhan, R. S. Winter, Q. Zheng, J. Yan, J. M. Cameron, D.-L. Long and L. Cronin, Angew. Chem., Int. Ed., 2015, 54, 14308.

11 (a) J. A. F. Gamelas, M. S. Balula, H. M. Carapuca and A. M. V. Cavaleiro, Electrochem. Commun., 2003, 5, 378; (b) C. Pichon, P. Mialane, A. Dolbecq, J. Marrot, E. Rivière, B. Keita, L. Nadjo and F. Sécheresse,
Inorg. Chem., 2007, 46, 5292; (c) Z. Zhang, Y. Qi, C. Qin, Y. Li, E. Wang, X. Wang, Z. Su and L. Xu, Inorg. Chem., 2007, 46, 8162.

12 R. L. Carlin, Magnetochemistry, Springer, Berlin, 1986.

13 J. Catterick and P. Thornton, Adv. Inorg. Chem. Radiochem., 1977, 20, 291. 